\title{
Idaho rural physician technology usage over time
}

\author{
Edward Baker*1, David Schmitz ${ }^{2}$, Sophia Brasil ${ }^{1}$, Lisa MacKenzie ${ }^{1}$ \\ ${ }^{1}$ Center for Health Policy, Boise State University, Boise, United States \\ ${ }^{2}$ Family Medicine Residency of Idaho, Boise, United States
}

Received: July 11, 2016

DOI: $10.5430 /$ jha.v5n6p14

\author{
Accepted: August 10, 2016 \\ Online Published: August 18, 2016 \\ URL: http://dx.doi.org/10.5430/jha.v5n6p14
}

\begin{abstract}
Objective: Health information technology (HIT) in rural settings has considerable potential to address rural health needs such as cost, access, and efficiency. This study contrasts the use of technology by Idaho rural physicians to identify differences in technology usage over time. The study includes information on technology factors such as internet databases, internet journals, e-publications, teleconferencing, electronic health records (EHRs) for patient care, and electronic physician education materials.

Methods: Surveys focused on the broad experience of practicing rural medicine were administered to rural physicians in Idaho who practiced in counties containing less than 50,000 people. Identical surveys were sent out in 2007 and again in 2012.

Results: Out of the 248 rural physicians who were successfully mailed the survey in 2007, responses were obtained from 92 for a response rate of $37.1 \%$. In 2012, the response rate was 35.3\% (89/252). Descriptive and inferential analyses were conducted in order to monitor and compare technology usage over time in the rural medicine workforce environment.

Conclusions: Comparative results across time periods indicated a significant increase in overall technology utilization by rural physicians. In addition, there was a trend of decreasing the disparities in technology utilization between gender, age, and employment groups. Among all groups of physicians in both 2007 and 2012, the highest technology usage was of internet databases, journals and e-publications.
\end{abstract}

Key Words: Rural physician technology utilization, Rural health information technology, Electronic medical records, Rural health care

\section{INTRODUCTION}

The use of health information technology (HIT) is an important aspect in providing efficient health care in the constant evolving United States health care system. ${ }^{[1]}$ Increasing the usage of HIT into the United States health care system intends to reduce health care costs, improve population health access and increase means of sharing health information to manage care more efficiently. ${ }^{[1]}$ Government programs, policy and incentive initiatives such as the American Recovery and Reinvestment Act of 2009, Centers for Medicare and Medicaid Services (CMS) incentive programs including meaningful use of electronic health record (EHR) systems are in place to help increase the usage of HIT. ${ }^{[2]}$ According to the Office of the National Coordinator (ONC) for HIT, HIT has the potential to be a tool of great importance in improving clinical operations and the health of patients. ${ }^{[3]}$ HIT shows promise in providing benefits to rural clinics that struggle with limited resources and limited workforce capacity. ${ }^{[4]}$

Many rural family physician workforce challenges exist in the U.S. health care system. There is only an approximate $11.4 \%$ of physicians in the United States practicing medicine in rural areas despite more than $19 \%$ of the population living

\footnotetext{
*Correspondence: Edward Baker, Prof.; Email: ebaker@boisestate.edu; Address: Center for Health Policy, Boise State University, 1910 University Drive, Boise, United States.
} 
in these remote locations. ${ }^{[5]}$ Implementation of HIT has been known to help in the recruitment and retention of physicians in rural areas. ${ }^{[6]}$ HIT has been identified as an area that might help meet the needs of rural health care providers contributing to workforce development by providing accurate and timely data to rural providers. ${ }^{[7]}$ A 2013 systematic review found that $75 \%$ of articles reviewed incurred a financial benefit including increased revenue as well as cost savings from HIT implementations. ${ }^{[8]}$ Technology in health care has been shown to have many other positive implications including increased financial and medical decision efficiencies, as well as decreased errors. ${ }^{[9]}$ The various technologies used in rural facilities that might help aid in the recruitment and retention of physicians are items such as EHR, telemedicine, videoconferencing, electronic means of continuing medical education, and remote monitoring technologies (RMTs). ${ }^{[4,9,10]}$

Best practices for utilizing HIT to contribute to delivering improved health care in rural and underserved areas have been identified. The strategies found to be useful are monitoring target population needs and reducing administrative costs by increasing HIT implementation and use. ${ }^{\text {[] }}$ Singh, Lichter, Danzo, Taylor \& Rosenthal, examined the adoption of HIT in rural and urban facilities using a survey targeting primary care offices. ${ }^{[11]}$ Findings indicated a relationship between the size of the facility and the adoption of EMR systems. In particular, this study reported that there were no significant differences in computer use or connectivity between populations living in rural and urban areas, but rural clinics and hospitals often lack the infrastructure and resources to implement these resources. ${ }^{[11]}$ These findings show that although rural populations stand to benefit from the implementation of EMRs, technical assistance and continued monitoring is necessary to decrease these gaps in utilization.

The focus of this paper is to contrast overall technology usage patterns from a 2007 Idaho rural physician workforce study to a subsequent 2012 study of rural physicians to identify differences in technology usage in rural areas of Idaho over time. ${ }^{[12,13]}$ This study addresses technology utilizations factors regarding internet databases, internet journals, e-publications, teleconferencing, EHRs for patient care, and electronic physician education materials.

\section{MethodS}

The following described methods were equivalent for both the original 2007 study and the 2012 follow-up study. ${ }^{[12,13]}$ The research methods were approved by the human subjects review board of the corresponding author for both the 2007 and 2012 studies.

\subsection{Survey development}

The survey included questions addressing the following areas: demographics, training, loan repayment, post-residency practice, scope of practice, technology utilization, work load and satisfaction with practice parameters. The specific wording of individual questions was drafted by the researchers with input from rural physicians and administrators. The 2012 survey was equivalent to the 2007 survey and only minor editorial differences were permitted. The final survey document can obtained from the corresponding author.

\subsection{Survey administration}

The Idaho Academy of Family Physicians (IAFP) administered the survey in both 2007 and 2012. Surveys were sent to IAFP members who practiced in counties where the population was 50,000 or less. The IAFP notified selected physicians by email of the study and then mailed them the survey. A follow-up email was used to maximize the response rate. The surveys were analyzed at the Center for Health Policy at Boise State University. The analysis employed descriptive and inferential statistics including $t$-tests Mann-Whitney $U$ tests, Chi-Square and Fisher's Exact tests.

\section{RESULTS}

Out of the 248 physicians who were successfully mailed the survey in 2007, responses were obtained from 92 for a response rate of $37.1 \%$. In 2012, the survey was successfully mailed to 252 rural physicians and was returned by 89 for a survey response rate of $35.3 \%$.

Table 1 contrasts Idaho rural physician technology usage from 2007 to 2012. In 2012, Idaho rural physicians reported significantly higher use of internet databases, journals, e-publications $(p=.020)$, teleconferencing or other internet technology $(p=.043)$, EHRs for patient care $(p<.001)$, and electronic physician education materials $(p=.004)$.

Differences in technology utilization by gender are contrasted in Table 2. In 2007 females had higher utilization rates for internet databases, journals and e-publications $(p=.034)$ and also accessed electronic physician education materials $(p=.008)$ at higher rates that their male counterparts. In 2012, no significant differences by gender were noted.

Table 3 represents differences in technology usage variables by age group ( $\leq 48$ years old, $>49$ years old). In 2007, younger physicians used internet databases, journals and e-publications $(p=.043)$ at higher rates than older physicians. In 2012, no significant differences by age group were noted. 
Table 1. Overall technology usage results across years

\begin{tabular}{|c|c|c|c|c|c|}
\hline \multirow{2}{*}{ Idaho Rural Physicians Who Utilize } & \multicolumn{2}{|c|}{2007} & \multicolumn{2}{|c|}{2012} & \multirow{2}{*}{$p$-value } \\
\hline & $\mathbf{n}$ & Yes (\%) & $\mathbf{n}$ & Yes (\%) & \\
\hline Internet databases, journals, e-publications & 91 & $76(83.5)$ & 89 & $84(94.4)$ & $.020^{*}$ \\
\hline Teleconferencing or other interactive technology & 90 & $33(36.7)$ & 89 & $46(51.7)$ & $.043^{*}$ \\
\hline Electronic health records for patient care & 91 & $43(47.3)$ & 88 & $71(80.7)$ & $<.001^{* *}$ \\
\hline Electronic physician education materials & 90 & $58(64.4)$ & 89 & $74(83.1)$ & $.004^{* *}$ \\
\hline
\end{tabular}

${ }^{*} p<.05 ;{ }^{* *} p<.01 ;$ two-tailed Chi-square test

Table 2. Differences in technology usage variables by gender by year

\begin{tabular}{|c|c|c|c|c|}
\hline \multirow{2}{*}{ Idaho Rural Physicians Who Utilize } & \multicolumn{2}{|c|}{2012 (\% Yes) } & \multicolumn{2}{|c|}{2007 (\% Yes) } \\
\hline & Male & Female & Male & Female \\
\hline Internet databases, journals, e-publications & $80.0^{\dagger}$ & $100.0^{\dagger}$ & 92.8 & 100.0 \\
\hline Teleconferencing or other interactive technology & 35.7 & 42.1 & 55.1 & 40.0 \\
\hline Electronic health records for patient care & 48.6 & 45.0 & 80.9 & 80.0 \\
\hline Electronic physician education materials & $58.0^{* *}$ & $90.0^{* *}$ & 81.2 & 90.0 \\
\hline
\end{tabular}

${ }^{* *} p<.01$, two-tailed Chi-square test; ${ }^{\dagger} p<.05$, two-tailed Fischer’s Exact test due to cell count minimums

Table 3. Differences in technology usage variables by age group by year

\begin{tabular}{|c|c|c|c|c|}
\hline \multirow{2}{*}{ Idaho Rural Physicians Who Utilize } & \multicolumn{2}{|c|}{2007 (\% Yes) } & \multicolumn{2}{|c|}{2012 (\% Yes) } \\
\hline & $\leq 48$ years old & $>49$ years old & $\leq 48$ years old & $>49$ years old \\
\hline Internet databases, journals, e-publications & $91.3^{*}$ & $75.6^{*}$ & 97.6 & 91.7 \\
\hline Teleconferencing or other interactive technology & 39.1 & 34.1 & 51.2 & 52.1 \\
\hline Electronic health records for patient care & 50.0 & 44.4 & 80.5 & 80.9 \\
\hline Electronic physician education materials & 73.3 & 55.6 & 90.2 & 77.1 \\
\hline
\end{tabular}

${ }^{*} p<.05$, two-tailed Chi-square test

Table 4. Differences in technology utilization variables by employment group by year

\begin{tabular}{llllll}
\hline \multirow{2}{*}{ Idaho Rural Physicians Who Utilize } & \multicolumn{2}{c}{ 2007 (\% Yes) } & & \multicolumn{2}{c}{ 2012 (\% Yes) } \\
\cline { 2 - 3 } \cline { 5 - 6 } & Employed & Not Employed & & Employed & Not Employed \\
\hline Internet databases, journals, e-publications & 90.0 & 79.7 & 92.1 & 95.5 \\
Teleconferencing or other interactive technology & $60.0^{* *}$ & $24.1^{* *}$ & 44.7 & 52.3 \\
Electronic health records for patient care & $30.0^{*}$ & $57.6^{*}$ & 81.1 & 77.3 \\
Electronic physician education materials & 63.3 & 64.4 & 76.3 & 88.6 \\
\hline
\end{tabular}

${ }^{*} p<.05 ;{ }^{* *} p<.01$; two-tailed Chi-square test

Table 4 demonstrates the differences in technology usage variables by employment group (employed or not employed). In 2007 employed physicians were significantly more likely to use teleconferencing or other interactive technology $(p=.001)$. In 2007, the independent physicians were significantly more likely to use EHRs for patient care $(p=.014)$. In 2012, no statistical differences by employment group were note.

\section{Discussion}

\subsection{Overall results}

Overall technology usage results from 2007 to 2012 for responding Idaho rural family physicians indicate significantly more technology usage across all assessed dimensions included in the survey. The increased usage over time could be related to factors previously detailed such as changes from healthcare reform, incentives to providers to use these technologies, the expected benefits of using health technology for workforce development, financial benefit, workflow challenges and continuing medical education. These findings suggest that more physicians are using technology overall and there is a significant increase over time. This is an area for further research.

\subsection{Gender}

In 2007 there was a significant difference between males and female respondents for technology usage areas including: 
(1) internet databases, journals, e-publications; and (2) electronic physician education materials. There seemed to be a shift in 2012 as there were no significant differences between males and females, narrowing the gap between males and female respondents indicating more usage of these technology factors across both genders in rural Idaho. Males increased their raw percentage technology usage from 2007 to 2012 across all areas and females increased their raw percentage technology utilization for the EHRs for patient care in 2012 It might be beneficial to explore these gender differences with further research.

\subsection{Age}

In 2007 physicians 48 years old and younger reported significantly higher use of internet databases, journals and epublications. Also in 2007, younger physicians reported higher raw percentage use of teleconferencing or other interactive technology, EHRs for patient care and electronic physician education materials. Physicians older than 49 years old increased their raw percentage technology usage in all four areas by 2012. The older age group decreased the gap between technology usage by age groups in 2012, and they reported higher raw percentage usage of teleconferencing or other interactive technology as well as EHRs for patient care than their younger counterparts. These changes in technology use by older physicians may represent the fact that younger physicians were more likely to be early adopters and that older physicians were slower to embrace technology in their practices. May and Smith have proposed a "Normalization Process Theory" to attempt to understand how some processes are more likely to become embedded in complex systems and their work may shed some light why older physicians were later technology adopters. ${ }^{[14]}$ It may also be that younger physicians were more comfortable with technology given that they were raised in a more technological environment.

\subsection{Employment}

In 2007, the employed group had significantly higher usage in teleconferencing or other interactive technology, whereas the non-employed group had significantly higher usage of EHRs for patient care. In addition, the employed group reported higher raw percentage utilization of internet databases, journals and e-publications. The usage of electronic physician training materials was slightly higher by those not employed. In 2012, there were no significant differences in technology utilization by employment group. However, the non-employed group had higher raw percentage technology usage across three of the four technology factors. In 2012, the employed group only had higher raw percentage rates in the use of EHRs for patient care. Across all factors and em-

Published by Sciedu Press ployment groups, raw percentage technology use increased from 2007 to 2012 except for teleconferencing or other interactive technology usage by the employed group which decreased from 2007 to 2012 in raw percentage terms. Nonemployed physicians seem to have been early adopters of the EHRs for patient care and also used electronic physician training materials more than employed physicians. This may be related to the fact that physician office technology solutions for EHRs for patient care were more easily integrated into smaller office practices and that larger, more complex technology solutions for owned practices took longer to deploy. The use of electronic physician training materials may suggest that non-employed physicians selected the most practical solution to meeting continuing education requirements that had the least impact on their practices.

\subsection{Research limitations}

Some degree of caution should be employed in reviewing these results. Although physicians answered the survey in relatively robust numbers in 2007 and 2012, less than half of the physicians who received a survey actually completed and returned the survey. These physicians may have different technology utilization patterns than those who returned the surveys. Moreover, some subsets of physicians had relatively small sample sizes which limits the statistical power to identify differences between groups of respondents.

\section{Conclusions}

Physicians and hospitals in rural and remote areas throughout the country are experiencing changes in their utilization of health technology. From 2007 to 2012, the majority of rural Idaho physicians increased their technology usage across the four identified factors of internet databases, journals, e-publications; teleconferencing or other internet technology; EHRs for patient care; and electronic physician education materials. In addition, there was a trend of decreasing the technology usage disparities between gender, age and employment status groups. Among every physician subset group in 2007 and 2012, internet databases, journals and epublications had the highest rates of use. Teleconferencing or other interactive technology had the lowest usage rates across every group for both years except for employed physicians in 2007, in which case EHRs had the lowest rates of utilization. Future technology utilization by rural physicians can be expected to increase across all gender, age and employment groups as health care technology matures and focuses on helping physicians to care for their patients.

\section{ACKNOWLEDGEMENTS}

This research was funded by the Idaho Department of Health and Welfare, Bureau of Rural Health and Primary Care 
through grants from the US Department of Health and $\mathrm{Hu}-$ man Services, Health Resources and Services Administration, Office of Rural Health Policy. Financial contributions to this research were also made by Boise State University, the
Family Medicine Residency of Idaho, the Idaho Academy of Family Physicians, Inc., and the Idaho Hospital Association.

CONFlicts OF INTEREST Disclosure

The authors declare they have no conflicts of interest.

\section{REFERENCES}

[1] Butin MB, Burke MF, Hoaglin MC, et al. The benefits of health information technology: a review of the recent literature shows predominantly positive results. Health Affairs (project Hope). 2011; 30(30): 464-71. PMid: 21383365. http://dx.doi.org/10.1377 /hlthaff. 2011.0178

[2] What is Meaningful Use? 2013. Available from: https://www.healthit.gov/providers-professiona ls/ehr-incentives-certification

[3] About ONC. 2014. Available from: http://www.healthit.gov /newsroom/about-onc

[4] Davis MM, Currey JM, Mpa:Ha SH, et al. A Qualitative Study of Rural Primary Care Clinician Views on Remote Monitoring Technologies. Journal of Rural Health. 2014; 30(1): 69-78.

[5] Fordyce MA, Chen FM, Doescher MP, et al. Physician Supply and Distribution in Rural Areas of the United States. 2007. Available from: http://depts.washington.edu/uwrhrc/uploads/ RHRC $\% 20$ FR $116 \% 20$ Fordyce.pdf

[6] Gagnon MP, Pollender H, Trépanier A, et al. Supporting health professionals through information and communication technologies: a systematic review of the effects of information and communication technologies on recruitment and retention. Telemedicine journal and e-health: the official journal of the American Telemedicine Association. 2011; 17(4): 269-74. PMid: 21476881. http://dx.doi.org $/ 10.1089 / \mathrm{tmj} .2010 .0175$

[7] Mpa MM, Rudman WJ, Hart-Hester S, et al. Leveraging Health Information Technology and Health Information Management in Rural America: A Health Summit Commentary. Journal of Rural Health.
2012; 28(1): 4-7. PMid: 22236309. http://dx.doi.org/10.11 11/j.1748-0361.2011.00383.x

[8] Low AF, Phillips AB, Ancker JS, et al. Financial effects of health information technology: a systematic review. American Journal of Managed Care. 2013; 19(19): 369-76.

[9] Olson JR, Belohlav JA, Cook LS. A Rasch model analysis of technology usage in Minnesota hospitals. International Journal of Medical Informatics. 2012; 81(8): 527-38. PMid: 22361157. http: //dx.doi.org/10.1016/j.ijmedinf .2012.01.008

[10] Curran V, Rourke L, Snow P. A framework for enhancing continuing medical education for rural physicians: A summary of the literature. Medical Teacher. 2010; 32(11): 501-8. PMid: 21039092. http://dx.doi.org/10.3109/0142159x.2010.519065

[11] Ranjit S, Lichter MI, Andrew Danzo BA, et al. The Adoption and Use of Health Information Technology in Rural Areas: Results of a National Survey. Journal of Rural Health. 2012; 28(1): 16-27. PMid: 22236311. http://dx.doi.org/10.1111/j.1748-0361. $2011.00370 . \mathrm{x}$

[12] Baker E, David S, Ted E, et al. Rural Idaho Family Physicians' Scope of Practice. Journal of Rural Health. 2010; 26(1): 85-89. PMid: 20105273. http://dx.doi.org/10.1111/j.1748-0361.2009 $.00269 . \mathrm{x}$

[13] Schmitz D, Baker E, MacKenzie L, et al. Assessing Idaho Rural Family Physician Scope of Practice over Time. Journal of Rural Health. 2015; 31(3): 292-299. PMid: 25640898. http://dx.doi.org/10. $1111 /$ jrh. 12107

[14] May C, Finch T. Implementation, embedding, and integration: An outline of Normalization Process Theory. Sociology. 2009; 43(3): 535-554. http://dx.doi.org/10.1177/0038038509103208 